\title{
THE BARRIERS IN THE IMPLEMENTATION PROCESS AND THE OPERATION OF INNOVATIVE URBAN TRANSPORT: THE CASE OF BRT JAKARTA
}

\author{
SYNTHIA ANGELINA, DIRK VALLÉE \& CONNY LOUEN \\ RWTH Aachen University, Institute for Urban and Transport Planning, Germany
}

\begin{abstract}
Rapid urbanization and motorization in developing countries are empirically engendering the unsustainable urban transport. Jakarta is now suffering from its negative consequences such as traffic congestion, accident, air pollution, noise, resources depletion, and environmental degradation. The implementation of Bus Rapid Transit (BRT) in Jakarta as one of the innovative urban transport policy in Indonesia is expected to overcome the urban transport problems and contribute to sustainability transition. Unfortunately, after a decade of BRT operation, the daily patronage has been declining over years and the traffic congestion in Jakarta is still deteriorating. There is a growing awareness of the governments of Indonesia towards more sustainable urban transport that states in the National MidTerm Development Planning 2015-2019 to give a priority for the improvement and development of rapid transit system in urban areas, including the further development of BRT Jakarta and its dissemination to other cities in Indonesia. However, for the effective urban transport improvement, the barriers which impede a shift to more sustainable transport need to be identified. This study aims to identify barriers encountered in the implementation of BRT Jakarta so that the question of why the progress towards sustainability has been slow through this system can be answered. Strategic Niche Management (SNM) approach is adopted to reveal the barriers in the implementation process and the operation of BRT Jakarta. The important measures in the implementation process such as decisionmaking framework, financing system, and approval procedure are described. The result shows that technological, government policy and political, and the control of infrastructure and maintenance aspects are the main barriers that hinder the effective implementation and further development of BRT Jakarta. The barriers identified in this study may be useful for the planners and policy makers in Indonesia and other developing countries to establish implementation-oriented strategies towards more sustainable urban transport.
\end{abstract}

Keywords: developing country, implementation process, public transport, sustainable transport, strategic niche management.

\section{INTRODUCTION}

Current transport regime in Jakarta faces considerable numbers of intractable problems such as congestion, accident, air pollution, noise, and resource depletion. Greenhouse gas emission (GHG) from transport sector in Jakarta accounts for 45 percent of the city's emitters [1]. These problems and related social, environmental and economic impacts showed that the current urban transport system may be considered as unsustainable. The necessity for an effective solution or system innovation has been proposed to achieve more sustainable transport regime in Indonesia's cities. According to the ministry of transport, before the bus rapid transit (BRT) Jakarta implementation, the economic loss due to congestion in this city were $\$ 1.4$ billion per year and this number is expected to increase up to $\$ 7.3$ billion a year if there is no improvement of the urban transportation system [2].

The national mid-term development planning in Indonesia (RPJMN 2015-2019) sets the priority to improve the urban public transport in order to tackle the transport problems in urban areas. As stated in Jakarta Transport Master Plan (JTMP) 2015, one of their priorities lies on the further development of the innovative road-based urban public transport system 
in Jakarta to provide a more attractive alternative to private vehicles [3]. Next to Jakarta, the development of BRT systems and its supporting facilities are also planned to be implemented in 34 other major cities in Indonesia. There are more than 1,100 BRT buses that have been operated in 17 Indonesian cities, which in total accommodate approximately 600,000 passengers per day [4].

BRT system is a bus-based high-quality mass rapid transit system that emulates the characteristics of rail-based transit system that are fast, comfortable, and reliable through its segregated lanes but with lower cost. The application of BRT system has emerged from North America and Europe which is now becoming the new solution for cities looking for cost effective transport. In Indonesia, BRT Jakarta is one of the innovative urban transport policies that has been operating since 2004. The development of BRT systems in Indonesia is part of the Nationally Appropriate Mitigation Action (NAMA) implementation using transport demand management (TDM) approach. Unfortunately, after a decade of BRT operation, the poor performance of BRT systems has shown by declining numbers of daily BRT patronage with 2,500 pax/day in 2006 compared to $1,850 \mathrm{pax} /$ day in 2014. This decline persists although government subsidies have increased significantly [5]. Moreover, the traffic congestion in Jakarta is still deteriorating while the growths of private vehicles were almost 10 percent per year during this period [6]. BRT Jakarta has difficulty attracting more passenger's due to the low level of service quality, lack of institutional capacity and lack of infrastructure facility [7].

The socio-technical configuration like BRT in public transport regime has its contribution to sustainability transition and shows multi-scalar dynamics of niche development [8]. For these reasons, theoretical analysis from the transition and niche formation concept were considered necessary for an understanding of how the existing BRT regime in Jakarta contributed to the regime-shift. Innovation from niche level in BRT case faces difficulties when they have to interact with the existing regime. The improvement needs long-term strategies since it causes intense barriers and results in opposition from stakeholders. A chance through the regime shift can occur once the opportunity opened such as political support from higher government level and financial assistance [9]. Barriers to the implementation of a sustainable urban transport occur at all levels of decision-making and all elements of urban sustainability so that for the further progress of the system, the difficulties that hamper the implementation process and operation need to be revealed.

The successful transition towards new regime could be achieved through experimenting in the niche. Kemp et al. [10] introduced strategic niche management (SNM) with the goal of stimulating learning process about the desirability of social transition for further development and application of new technology. SNM has been applied as a policy tool that analyzed the ex-post transition experiments in niche creation in order to advise the policy makers about sustainable policies for the future [11]. Successful niche formation indicates by regime transformation from technological niche to market niche (shift of embedding regime). It requires specific learning modes and institutional embedding patterns, therefore analyzing these aspects could reveal difficulties faced by the new technology [12].

Barriers engender by the initial BRT implementation need to be addressed before the further development of this system. The effectiveness of current policy approach in promoting sustainability innovation in Jakarta is not yet proven. Therefore, an appropriate policy framework for effective implementation is vastly necessary. Supported by SNM concept, this paper aims to identify the barriers of the BRT regime in Jakarta. Barriers identified from this paper are essential for the consideration of factors for providing an implementation-oriented strategy towards the effective improvement of BRT system in Jakarta as well as its dissemination to other cities in Indonesia. 
First Strategic Niche Management (SNM) concepts are outlined, while particularly paying attention to the learning process as a tool to identify barriers to the innovative urban transport policy implementation. The next section elaborates the BRT Jakarta implementation process in term of decision-making framework, financing system, and approval procedure for understanding the difficulties faced during the implementation. The paper then describes the existing condition of urban transport in Jakarta and the operation of BRT Jakarta. Based on the SNM concept, some of the barriers of the introduction new policy/technology are categorized and analyzed. The outcome of this analysis can help identify why there is a slow transition towards sustainability in Jakarta and the barriers that hinder the successful implementation of BRT Jakarta can be exposed.

\section{THE CONCEPT OF STRATEGIC NICHE MANAGEMENT (SNM)}

In the transition process, niches play an important role in the adaptation of new regime as well as wider diffusion and development of a new system or technology including innovative public transport system [13], [14]. Kemp et al. [10], found that strategic niche management (SNM) is a significant strategy to develop and control in a protected space for application of promising technology. SNM aims to learn about the attractiveness and stimulating the further development of the new technology. This strategy is necessary for governments as a policy tool to manage the process of niche formation, development and encouragement for regimeshift. There are three internal SNM process for successful development of a technological innovation: Coupling of expectation, network formation, and learning process. The learning process is essential to make the new technology become socially embedded and provide the suitable niche management policy.

The implementation of the new transport development encounters some difficulties as they challenge the dominant regime. Ieromonachou et al. [15], has proved that the use of SNM approach analysis would be essential to identify the barriers that are faced by the actors involved during the implementation such as a lot of conflicts against current political, social, cultural, institutional, and economic restraints. SNM analysis is systematical to learn about the integration of technical, economic force, information needs, and acceptability in terms of social and political. However, renewing the existing system requires the stimulation of articulation and learning process because the knowledge of the public and actors involved is limited or even non-existent. These limitations prevent them from inventing the socio-technical system [16]. The learning process in SNM work is important to identify the barrier to the introduction and development of new technology.

There are some factors that are responsible for the slow transition to more sustainable transport. These factors are considered as the barriers faced during the implementation of the new technology or policy in transport. These factors which are mentioned in the learning process in SNM concept seems to be useful for the barriers identification analysis in this paper [10], [12]. First, the technological factors occur because of the new technology are often not suitable for the existing transport systems and sometimes needs complementary technology that is perhaps difficult to establish in terms of supply and cost. Second, the government policy often consists of uncertainties of the need for specific new technology and the existing regulatory framework often hampers the development of the new technology. Third, the cultural factor that expresses the status symbol by owning a car will inhibit the development of new public transport innovation and the unfamiliarity with new technology often leads to hesitation because all actors compare the new technology to the dominant technology. Fourth, the demand factors which occurs because there is no evidence that the new technology will succeed, there are some doubts on customers' perception. Fifth, the infrastructure and maintenance factors that required to support the operation of the new 
technology. Sixth, the undesirable societal and environmental effects of new technology also should take into consideration since the introduction of new technology could tackle some problems but the risk may be unavoidable and could create the new ones.

Supported by the SNM theory in term of learning process, we employ some aspects in the learning process to help to identify some barriers that hampered the development of BRT Jakarta. First, to obtain a deep understanding of the implementation of BRT Jakarta, we elaborate the decision-making framework, financing system, and approval procedure. This analysis is based on some key knowledge documents such as journal articles, planning guides, and policy documents that correlated to the implementation of BRT. Second, to address some issues in the operation of BRT Jakarta, we describe the existing condition of BRT Jakarta's operation and highlight some essential information such as demography of Jakarta, traffic condition, route development, passengers, productivity, and subsidy allocation. The data were gathered from the statistical data, project reports, and journal articles about the BRT Jakarta. Finally, to discover the barriers both in the implementation process and operation of BRT Jakarta, we refer to the learning process aspects in the SNM theory which is appropriate to identify the barriers in the implementation of innovative urban transport policy.

\section{THE IMPLEMENTATION PROCESS OF BRT JAKARTA}

The implementation process forms a temporal series of interrelated measures that should be effectively unfolded to intensify the quality implementation. Any effective innovation requires a high-quality implementation which may be influenced by some aspects. Numerous studies have examined the implementation process of sustainable urban transport concept which advanced our understanding of how it transpired e.g., [17]-[19]. Based on these studies, several aspects of the implementation process such as (1) decision-making framework, (2) financing system, and (3) approval procedure are indicated as crucial elements that affect the quality implementation. By analyzing these aspects, difficulty factors faced during the implementation of BRT Jakarta may be revealed.

\subsection{Decision-making framework}

BRT Jakarta was implemented through a cooperative work involving provincial government, planning agencies, and public transport provider. The implementation of BRT Jakarta was supported by the ideas and expectation of the former Governor of Jakarta. The objectives of BRT Jakarta implementation are to provide better urban public transport to the citizens of Jakarta, alleviate the notorious congestion, and reduce greenhouse gas (GHG) emissions [20]. Achieving the successful BRT system implementation is a complicated issue. The implementation requires an appropriate planning and coordination among various stakeholders [21]. The decision-making of BRT Jakarta reflects the top-down approach. The combination of vision-led and plan-led considering that the idea from Jakarta's Governor Sutiyoso and current urban transport plans are the most significant elements. He was then reelected partly due to his vision to realize the implementation of BRT Jakarta [22]. The topdown approach resulted in faster implementation and less initial conflicts between agencies [23]. May et al. [19] stipulate that the vision-led decision-making approach involves a leader who has a clear expectation of the future city. The plan-led decision-making approach involves the specified objectives and problems that need to be tackled, identify possible measures to solve those problems, and choose the best solution to be implemented.

The plan for the construction of the metro system in Jakarta was hampered by the economic crisis, therefore, it led the Governor to prioritize the implementation of BRT 
system based on the success story from BRT system in Bogota which has shorter construction process and lower cost than the metro system [22]. Although the decision-making approach of BRT Jakarta is combined out of vision-led and plan-led, there are no clear or enforced measures of making the decision. Furthermore, the initial planning of this system did not refer to its potential demand, as it only serves one-third of the potential demand [24]. Difficulties in the quality of data due to fast growth situation in cities in developing countries hinder the effective planning since the accurate model heavily based on the data availability [25]. However, the vision-led decision-making such as in BRT Jakarta faces many problems when the leader is out of office. After Sutiyoso left the Governor position in 2007, the development of BRT was reduced to a lower priority grade while the planning for LRT and MRT construction gain more attention [2].

In the planning process, BRT Jakarta obtains support from Institute for Transportation \& Development Policy (ITDP) and United Nations Environment Programme (UNEP), with funding provided by the Global Environment Facility (GEF) as the catalyst and lent the technical assistance to help build the political confidence and system management for BRT implementation and improvement [26]. BRT Jakarta is operated by the public authority under the Jakarta Municipal Government, so called TransJakarta including managing the bus operation which is run by nine different bus companies. Some of the bus operators established from the overlapped existing bus operators with BRT Jakarta routes, while the others were the selected bus operators based on tendering process. Using "buy the service" system, these bus operators are paid per kilometer travelled and should fulfil the standard level of service [3].

\subsection{Financing system}

The cost for the construction of BRT system is relatively low in comparison to other mass rapid transit alternatives, therefore loans and outside financing are unnecessary even for developing cities to fund the BRT construction [26]. The first $12.9 \mathrm{~km}$ corridor of BRT Jakarta was constructed in nine months and at a cost US\$29 million which is funded by the municipal budget. Based on the technical review by ITDP before the operation of BRT Jakarta first corridor, the report showed that the BRT Jakarta will never financially selfsufficient if it only implements the initial $12.9 \mathrm{~km}$ corridor without removing the overlapped conventional bus lines [20]. Therefore, the municipal government has been an attempt to integrate BRT Jakarta with existing bus operators and has been continuing the construction until now with 12 corridors, which will be expanded up to 14 corridors to create an integrated system. The construction cost of BRT Jakarta corridor 1-4 such as infrastructures, buses procurements, facilities, and bus service payment was entirely funded by the municipal budget. In the BRT system improvement, the financing of infrastructure and administrative cost for the following corridors up to 12 corridors was funded by the municipal government, in-kind financial contribution from ITDP, and mobilized co-financing from other agencies [27]. The operations of BRT Jakarta obtain funds from ticket sales and provincial subsidy. Fare revenue of BRT Jakarta is managed by TransJakarta; however, it is still insufficient to cover the operating cost and other expenses. TransJakarta has no financial control for the infrastructure cost. The construction and maintenance of BRT Jakarta lanes are funded by the Jakarta agency of public works, while the bus maintenance carried out by each responsible bus company. Municipal government provides subsidies for BRT Jakarta operation in order to keep the affordable flat fare system of IDR 3500 (USD 0.28) or IDR 2000 (USD 0.16) in the morning period (5-7 AM). The amount of BRT Jakarta fare subsidy is almost 40 percent of the actual cost in 2008 . The flat fare system attracts long distance 
passenger, while most of the short distance passengers choose a less cost and faster mode such as paratransit. The operation of BRT Jakarta remains deficit of 33.4 percent after four years of operation. The fare of BRT Jakarta is decided by the municipal government and is affected by the fluctuation of the oil price [28].

In contaminant with the corridor expansion, the increase in annual maintenance cost and labor cost, the operational cost also increased significantly. If there is no enhancement of passengers, the amount of subsidy needs to be increased in order to keep the flat fare. This condition will lead to being economically unsustainable in the future. According to Kogdenko [29], BRT Jakarta has the lowest investment cost-per-kilometer compared to BRT system in Delhi and Beijing. With revenue US\$ 32.2 million/year from the operation of the system, the payback time is about 6 years which is lower than other BRT systems.

\subsection{Approval procedure}

The proposal from the former governor of Jakarta, Sutiyoso, to implement the BRT system in Jakarta was literally a new concept of public transport in Indonesia, while the public view for public transport was generally poor at that time. Cars and motorcycles become more popular and generating intractable congestion problems. Therefore, the BRT system implementation required a comprehensive communication strategy to prevent the refusal from the involved parties [20]. On the implementation phase of BRT Jakarta, the interference from the people using the corridors that affected by the construction was unavoidable. This situation led to postponing instruction of corridor 1 construction from the ministry of transport, but Sutiyoso stands on his commitment to realizing the BRT Jakarta hence he intensified the construction and advanced the opening date one month forward [2]. He conducted the communication approach by providing more publicity in the implementation plan to the public. This communication approach was done through the advertisements on television regarding the BRT proposals. The effort for intense public consultation led to more public acceptance for the construction of BRT Jakarta. However, in the case of BRT Jakarta, the technical, financial, social and economic assessments of various alternatives are not the fundamental aspect of making the decision. The responsible bodies made the decisions and then presented them to the key decision makers for approval. The key decision makers are sometimes not conscious of other alternatives to perform the approval procedure. The operation of BRT Jakarta performs by the existing operators which are transformed into a consortium through direct negotiations. This decision was made by the authority because of the fear of protest from the conventional bus operators [23].

\section{INTRODUCE THE NEW SYSTEM INTO THE CITY (BRT OPERATION)}

Intense growth and urbanization in Jakarta are sprawling the capital. There were over 9.6 million inhabitants in Jakarta by 2010, but due to the commuting trips from the surrounding cities to Jakarta during the workday, the population swells to approximately 12 million people in the city. The population density is 14,464 per square kilometer. Jakarta has spatially and economically expanded into the metropolitan region, so called Jabodetabek (derived from the proximate cities - Jakarta, Bogor, Depok, Tangerang, Bekasi). This urban agglomeration area comprised more than 27 million inhabitants which were about 12 percent of the country population [30]. In terms of spatial structure, the land use change in Jakarta leads to the conversion of almost one-quarter land in Jakarta from non-urban uses for agriculture and water into urban uses for commerce, housing, and industry that suppress the 
remaining green area in the city [31]. Beyond its increased population, rapid economic and social growth in Jakarta has paved the way for rapidly escalating numbers of motor vehicle use and ownership. It is calculated that 75 percent of household in Jakarta own one or more motorcycles and 25 percent of household own one or more cars [6]. There are more than 12 million motor vehicles clogging the Jakarta's road and more than 70 percent of them are motorcycles [30]. Jakarta still faces complex challenges in terms of infrastructure and planning due to its institutional, financial, technical matters. Therefore, this city is still struggling with various urban transport problems, particularly massive traffic congestion.

After the economic crisis had passed, the Governor of Jakarta, Sutiyoso in 2001 decided to implement the BRT system [20]. BRT Jakarta requires a relatively low cost to be implemented because the infrastructure and equipment to support this system only need minor physical construction to the roadway. The total capital cost of BRT Jakarta is US\$1.4 million per kilometer and it was the lowest capital cost compared to other cities in the world that implement the similar system [23].

In 2004 the first corridor of BRT Jakarta was officially operated as the first full BRT system in Asia. In the beginning year, with one corridor (Blok M-Kota Station) of 13.6 kilometers, BRT Jakarta carried approximately 52,000 pax/day. During the weekdays, the BRT load factor was 91 percent and reached 143 percent during the evening peak hours [32]. Since the performance of the first corridor of BRT Jakarta reported as promising by some evaluation studies [20], [33], [24], the municipal government of Jakarta decided to continue the development of this system. Until 2013, there are 12 corridors along $202.9 \mathrm{~km}$ of BRT route and planned to extend up to the full 15 corridors. These corridors have been integrated with its cross routes, sub-urban routes, and feeder routes.

In concomitant with the route development, the passenger demand has also increased. With the highest passenger demand in 2011 of 378,000 pax/day, this system still cannot reach its planned increase of $600,000 \mathrm{pax} /$ day. The passenger demand showed a declining number of 3 percent in 2012 and then kept stabilized even after the operation of corridor 12 in 2013 [5]. Instead of no significant improvement of the BRT's performance, the declining number of passengers is also caused by the high increase in fuel subsidy in 2011 and 2012, which counted up to $4.1 \%$ of Indonesian GDP [34]. This fuel subsidy is not sufficiently well allocated to accurately compensate the poor household, the middle to high-income household also gets the benefit of the cheap oil price. Besides that, there is no policy to control the private vehicle ownership, which is currently very cheap and easily obtained. Moreover, government's policy of low-cost green car in 2013 made the owning car more attractive than riding the BRT Jakarta.

In terms of productivity, it stagnates decreasing since 2006 upwards despite its lower fare at IDR 2,000 per one-way trip from 5:00-7:00 AM and at IDR 3,500 for the rest of the day, which equivalent to USD 0.16 and USD 0.28 (exchange rate in December 2014). The operation of BRT Jakarta is still being subsidized for 14 percent of the cost per passenger [35]. The peak load of BRT Jakarta could only carry 3,600 passengers per hour per direction with very low average commercial speed of $15 \mathrm{~km} /$ hour. It operates generally below the maximum capacity, nevertheless, based on the field observation, significant capacity constraint appear in the system since there are still long queues in the BRT stations. This occurs because the problems on its design (high floor buses with only a single door) and operational that cause inefficient passenger loading [36].

With the poor performance, the number of private vehicles on the road networks remains to increase and the congestion still cannot be alleviated. The most used mode of transport in Jakarta in 2010 was the motorcycle, it counted 53 percent of trips while the mode share of the car was 20 percent. Public transports including BRT Jakarta made 27 percent of trips [6]. 


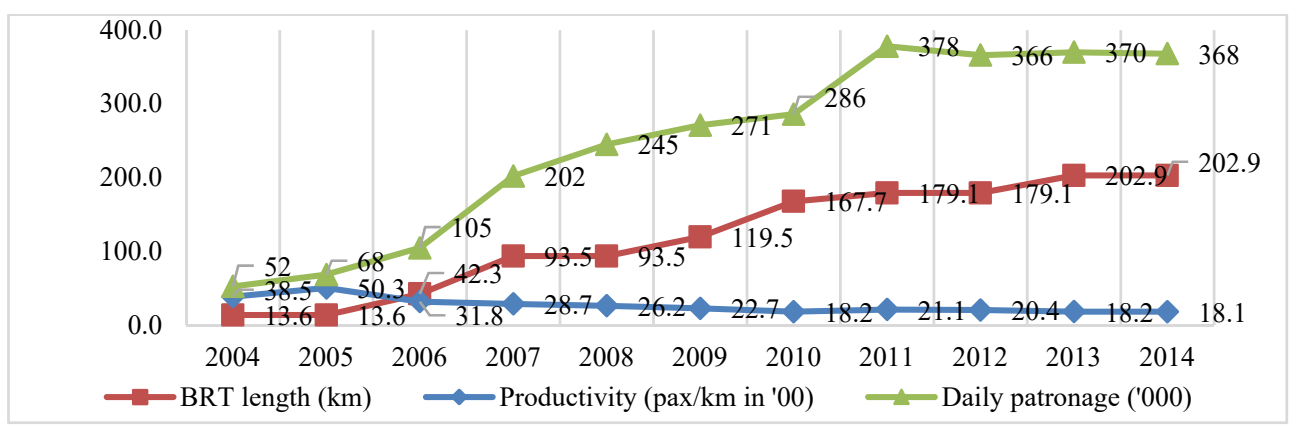

Figure 1: Passenger demand, productivity, and BRT length from 2004-2014 [5].

According to the World Bank study in the beginning year of BRT implementation, 67 percent of BRT passengers were the former commuters on the conventional bus system, 14 percent from private car users, 6 percent from motorcycle users, 5 percent from taxi users, and 6 percent from walking [24]. In 2012, BRT Jakarta post evaluation surveys by United Nation Environment Program (UNEP) asked 10 percent of BRT Jakarta passengers about their alternative mode if BRT Jakarta does not exist. The result showed that 72 percent of the passengers will choose the conventional bus system, 5 percent will choose cars, 9 percent will choose motorcycles, 12 percent will choose taxis (car taxi, motorcycle taxi, bajaj), and 0.3 percent will choose walking [27]. It can be concluded that most of the BRT passengers are still from the former conventional bus system and there is no significant mode shift by private car and motorcycle passengers. The car and motorcycle users choose to use BRT even if they own one or more private vehicles because they found that BRT is faster and cheaper. BRT Jakarta could save approximately 10 minutes travel time per passenger trip. This system also contributed to the reduction of greenhouse gasses in 2012 of 0.15 ton annually per daily BRT passenger [5].

Wright [37], emphasizes that the revolutionary approach of BRT systems in cities can only be permanently successful if the political leaders are highly motivated upon a wider vision towards the improvement of this system. The limitation of the initial BRT Jakarta operation perhaps due to a weak initial vision and political will, which leads to the system quality impediment. Based on the study of public transport users' preferences in Jakarta, safety and security improvement are important factors that explain the unobserved construct of an improvement policy due to passenger dissatisfaction with the bus driver. On the other hand, this study shows that the respondents give positive responses to fare increases if the problems are solved after the implementation of the improvement policies [38]. Moreover, BRT Jakarta encounters its main threat to compete with cars and motorcycles, which provide better flexibility and convenience. The success for further BRT development depends on the better understanding of BRT planning and design systems based on experiences from other cities. BRT systems should be integrated into the overall public transport system and embedded in city and land-use planning [39].

\section{THE BARRIERS IDENTIFICATION}

The BRT system achieves the transformation of the urban transport system by the connection and interaction of various actors and networks within social and technical dimensions in the city, therefore it becomes a promising new alternative mode and widely accepted as the solution of urban mobility problems [9]. The dissemination of BRT system in urban areas 
across the globe requires the actor network that shapes the protective space in order to facilitate the niche development. The international NGOs such as ITDP and EMBARQ are the biggest project catalyst supporting the implementation of BRT systems. They contribute in giving advice and support in planning, funding, and procedure of BRT implementation in a city based on best practice lesson from the previous projects. However, the national governments are also essential actors regarding the funding for the BRT project since the decision to implement the BRT contained in the national decision. On a national level, there is a "ripple effect" where one system triggers the establishment of more systems within a nation as another mechanism of raising diffusion. For example, after the BRT system in Jakarta was opened in 2004, the low-quality imitator system sparked in Indonesia's small cities. Although they retained some of the elements, the other crucial factors required for a BRT system standard are ignored. The local actors such as the expert from the universities also play an important role facilitating the knowledge exchange that leads to the dissemination of BRT [8]. These actors fostering the creation of the niche protection space of BRT that enable the transformation of the technological niche into the market niche.

Stimulating the learning process as the part of SNM perspective aims to discover the barriers in order to develop the innovations successfully. Learning means a range of processes and the results that are not known at the beginning of the introduction, therefore actors need to promote the technology articulation, market, and other factors. However, there are some barriers that hampered new sustainable transport concept being introduced into the market although their benefits to society are proved [12]. As the new urban transport concepts, there are some barriers that prevent the improvement and the dissemination of the BRT system. The implementation of BRT Jakarta faces technological barriers since it requires complementary technology such as a GPS-driven control system in order to keep a constant headway and manage the green wave at the intersection. Without such technologies, this system leads to service variability problems and vehicle bunching because of the delay at the intersection. Operational inefficiencies also caused by an unintegrated fare system. Fares of BRT Jakarta are collected off-board in order to prevent too long dwell times and fare evasion, but with this conventional ticketing system, there is no integrated fare with the feeder system nor with other urban public transport in Jakarta [40]. An integrated and reliable ticketing system is needed to ensure the reliability of BRT Jakarta. Non-captive users will shift to more robust travel alternatives such as car or motorcycle, which leads to more congestion if the unreliable service still occurs. The system performance and passenger usage level will continue to decline with the lack of these technologies.

The government policy and political factors often put unclear messages about the need and benefit of such technology. In the case of BRT Jakarta, when the leader who promotes the BRT Jakarta's implementation out of his office, the development of this system faces some delays due to the reallocation of unspent money to other projects. There is no clear medium term financial plan that integrates the capital funds with recurrent budget needs even though the substantial funding is provided yearly [27]. Moreover, the existing regulatory framework could prevent the new technology development towards sustainability. As stated on the national mid-term development planning in Indonesia, the priority is to improve the mass urban public transport with the intention of congestion reduction in urban areas. On the other hand, the low-cost green car policy in Indonesia which was established in 2013 has contributed to the increased growth of car ownership with almost 10 percent [41]. Although the goal of this policy is establishing greener and environment-friendly vehicles, but without a proper control of this system leads to increasing number of car ownership. In addition, congestion leads to great economic loss of $\$ 1.5$ billion per year in Jakarta and is expected to raise up to $\$ 7.3$ billion by 2020 if there are no change of the transportation system [2]. 
Another policy that hampers the improvement of urban public transport in Indonesia is the fuel subsidy. As long as the use of private vehicle is cheaper and more flexible than the public transport, there will be no change of people's mode choice [42]. The cultural factor that expresses the status symbol by owning a car will inhibit the development of new public transport innovation. Other factors such as the unfamiliarity with new technology often lead to hesitation because all actors compare the new technology with the dominant technology. The government should provide more policies to push the number of private vehicle ownership and reduce the use of the private vehicle as the primary mode of travel.

The adaptation of the infrastructure and maintenance control to support the new technology may be required. However, the factors such as investment, cost, and the responsible person could cause some problems. The weak control of the institutional structure engenders some problems regarding the maintenance of the fleet and routes, budget allocation for the infrastructure, and human resources quality. The BRT Jakarta is still incapable of accommodating the overwhelming passenger demand at the peak hours, which often encounter a crush load. This condition leads to poor social impacts such as inconvenient, criminality, and sexual harassment. Poor maintenance of the fleet causes the BRT Jakarta runs under the BRT standard which generates poor passenger perception and pollution in the city. The new technology could tackle some problems but the risk may be unavoidable and could create the new ones such as these undesirable social and environmental effects.

\section{CONCLUSION}

Realizing the plan for BRT Jakarta improvement and further dissemination to other cities in Indonesia requires proper strategies. Therefore, barriers that hampered the implementation of BRT Jakarta need to be addressed beforehand. From the analysis, we can conclude that the understanding of the crucial elements in the implementation process such as decision-making framework, financing system, and approval procedure are essential for further development of BRT Jakarta. The BRT niche analysis and Strategic Niche Management (SNM) approach help to indicate the barriers in the implementation process and operation practice based on some aspects of the learning process. BRT Jakarta faced some barriers in terms of technological, government policy and political, and the control of infrastructure and maintenance. BRT Jakarta needs some complementary technology such as GPS-driven control and integrated ticketing systems to increase the level of its performance. The government policy should provide more push approaches to alleviate the use of private vehicles. Moreover, from the institutional perspective, BRT Jakarta needs more control in the infrastructure and maintenance to prevent undesirable social and environmental problems. The identification of these barriers is necessary to be taken into consideration by the planners and policy makers when planning the implementation-oriented strategies for the improvement of BRT Jakarta towards a more sustainable urban transport in Indonesia.

\section{REFERENCES}

[1] Institute for Global Environmental Strategies (IGES), Final report: study on carbon governance at sub-national level in Indonesia case study Jakarta Province, 2011.

[2] The World Bank Group, The soft side of BRT: Lessons from five developing cities, Washington DC, 2012.

[3] Ministry of Transport Republic of Indonesia, Jabodetabek Transportation Master Plan Year 2015-2019, Jakarta, 2015.

[4] Ministry of Transport Republic of Indonesia, Strategic Planning Ministry of Transport Year 2015-2019, Jakarta, 2015. 
[5] Sayeg, P., Post evaluation of a decade of experience with Jakarta's Transjakarta Bus Rapid Transit System. Proceedings Australasian Transport Research Forum, 2015.

[6] Ministry of Transport Republic of Indonesia. Land Transportation in Figures 2014, Jakarta, 2015.

[7] Dalkmann, H., Final Report: Case study of a transport MRV NAMA: TDM Measures in Jakarta, Indonesia. Applicability of Post 2012 Climate Instruments to the Transport Sector (CITS) Project, 2010.

[8] Sengers, F. \& Raven, B., Toward a spatial perspective on niche development: The case of bus rapid transit. Environmental Innovation and Societal Transition 17, pp. 166$182,2015$.

[9] Dugand, S. M. et al., Lesson from the spread of bus rapid transit in Latin America. Journal of Cleaner Production 50, pp. 82-90, 2013.

[10] Kemp, R., Schot, J. \& Hoogma, R., Regime shifts to sustainability through processes of niche formation: The approach of strategic niche management, Technology Analysis \& Strategic Management, 10(2), pp. 175-198, 1998.

[11] Raven, R., van den Bosch, S. \& Weterings, R., Transitions and strategic niche management: towards a competence kit for practitioners, Int. J. Technology Management, 51(1), pp. 57-74, 2010.

[12] Hoogma, R., Kemp, R., Schot, J. \& Truffer, B., Experimenting for Sustainable Transport: The approach of Strategic Niche Management, Spon Press, New York, 2002.

[13] Loorbach, D., Transition management for sustainable development: A prescriptive, complexity-based governance framework, Governance: An International Journal of Policy, Administration, and Institutions, 23(1), pp. 161-183, 2010.

[14] Weber, M., Hoogma, R., Lane, B. \& Schot, J., Experimenting with Sustainable Transport Innovations: A Workbook for Strategic Niche Management, Seville/Enschede: Universiteit Twente, 1999.

[15] Ieromonachou, P., Potter, S. \& Enoch, M.P., Adapting strategic niche management for evaluating radical transport policies - The case of the Durham road access charge scheme, International Journal of Transport Management, 2 (2), pp. 75-87, 2004, DOI:10.1016/j.ijtm.2004.09.002.

[16] Raven, R.P.J.M., Strategic Niche Management for Biomass: A Comparative Study on the Experimental Introduction of Bioenergy Technologies in the Netherlands and Denmark, Eindhoven University Press, 2005.

[17] Matsunaga, H. \& Magdy, M., How to fill the implementation gap for inclusive growth: Case studies covering urban transportation sector development in Egypt, Global Economy and Development, Working Paper 85, 2015.

[18] Wefering, F., Rupprecht, S., Bührmann, S. \& Baedeker, S.B., Guidelines. Developing and Implementing a Sustainable Urban Mobility Plan, European Union, 2013.

[19] May, A.D. et al., Decision Maker's Guidebook, 2005.

[20] Institute for Transportation \& Development Policy (ITDP), Trans-Jakarta Bus Rapid Transit Technical Review, 2003.

[21] Wright, L., Latin American Busways: moving people rather than cars, Natural Resources Forum, 25(4), pp. 121-134, 2001.

[22] Matsumoto, N., Analysis of policy processes to introduce Bus Rapid Transit systems in Asian cities from the perspective of lesson-drawing: Cases of Jakarta, Seoul, and Beijing, Air Pollution Control in the Transportation Sector. Institute for Global Environmental Strategies, Hayama, pp. 351-376, 2007. 
[23] Hidalgo, D. \& Carrigan, A., Lessons learned from major bus improvements in Latin America and Asia, EMBARQ: Modernizing Public Transport, World Resources Institute, 2010.

[24] Ernst, J., Initiating Bus Rapid Transit in Jakarta, Indonesia. Transportation Research Record: Journal of the Transportation Research Board, pp. 20-26, 2005.

[25] Emberger, G., Pfaffenbichler, P., Jaensirisak, S. \& Timms, P., Ideal decision-making processes for transport planning: A comparison between Europe and South-East Asia, Transport Policy, 15, pp. 341-349, 2008.

[26] Wright, L. \& Hook, W., Bus Rapid Transit: Planning Guide, Institute for Transportation \& Development Policy (ITDP), 2007.

[27] Sayeg, P. \& Lubis, H.A., Terminal Evaluation of the UNEP GEF Project: Bus Rapid Transit and Pedestrian Improvements Project in Jakarta, 2014.

[28] Japan International Corporation Agency (JICA), Project for the Study on Jabodetabek Public Transportation Policy Implementation Strategy in the Republic of Indonesia (JAPTraPIS), 2012.

[29] Kogdenko, N., Successfulness of Bus Rapid Transit Systems in Asia: Ex-post Evaluation, University of Groningen, 2011.

[30] Statistics Indonesia (BPS), Statistical Yearbook of Indonesia, 2015.

[31] World Bank. Jakarta - Urban challenges in a changing climate. Washington, DC: World Bank, 2011.

[32] Susilo, Y.O., Santosa, W ., Joewono, T.B. \& Parikesit, D., A reflection of motorization and publictransport in Jakarta Metropolitan Area, IATSS RESEARCH, 31(1), pp. 5968, 2007.

[33] Institute for Transportation \& Development Policy (ITDP), Making TransJakarta Busway a world class BRT system, 2004.

[34] Asian Development Bank (ADB), Fossil Fuel Subsidies in Indonesia: Trends, Impacts, and Reforms, Asian Development Bank, Mandaluyong City, 2015.

[35] Steer Davies Gleave (SDG), Jakarta feeder bus study, 2011.

[36] Carrigan, A. et al., Social, Environmental and Economic Impacts of BRT Systems, World Resources Institute, 2010.

[37] Wright, L., Sustainable Transport: A Sourcebook for Policy-makers in Developing Cities. Module 3b: Bus Rapid Transit. Deutsche Gesellschaft für Technische Zusammenarbeit (GTZ), 2003.

[38] Joewono, T.B., Tarigan, A.K.M. \& Susilo, Y.O., Road-based public transportation in urban areas of Indonesia: What policies do users expect to improve the service quality? Transport Policy, 49, pp. 114-124, 2016.

[39] Vuchic, V.R., Light Rail and BRT: Competitive or Complementary? Public Transport International, 5, pp. 10-13, 2005.

[40] Sengers, F. \& Raven, B., Toward a spatial perspective on niche development: The case of Bus Rapid Transit. Environmental Innovation and Societal Transitions, 17, pp. 166$182,2015$.

[41] Statistics Indonesia (BPS), Transportation Statistics of DKI Jakarta, 2015.

[42] Maimunah, S. \& Kaneko, S., MRT as Climate Policy in Urban Transportation. Climate Change Policies and Challenges in Indonesia, Springer Japan, pp. 243-264, 2016. 